\title{
Effects of a proinflammatory response on metabolic function of cultured, primary ruminal epithelial cells
}

\author{
C. Kent-Dennis and G. B. Penner* (i) \\ Department of Animal and Poultry Science, University of Saskatchewan, Saskatoon, SK, Canada, S7N 5A8
}

\begin{abstract}
Inflammation of ruminal epithelium may occur during ruminal acidosis as a result of translocation and interaction of ruminal epithelial cells (REC) with molecules such as lipopolysaccharide (LPS). Such inflammation has been reported to alter cellular processes such as nutrient absorption, metabolic regulation, and energy substrate utilization in other cell types but has not been investigated for REC. The objectives of this study were to investigate the effects of LPS on metabolism of short-chain fatty acids by primary REC, as well as investigating the effects of media containing shortchain fatty acids on the proinflammatory response. Ruminal papillae from 9 yearling Speckle Park beef heifers were used to isolate and culture primary REC. Cells were grown in minimum essential medium (MEM) for $12 \mathrm{~d}$ before use and then reseeded in 24-well culture plates. The study was conducted as a $2 \times 2$ factorial, where cells were grown in unaltered MEM (REG) or medium containing $2 \mathrm{~m} M$ butyrate and $5 \mathrm{~m} M$ propionate (SCFA) with $(50,000 \mathrm{EU} / \mathrm{mL}$; +LPS) or without LPS (-LPS) for $24 \mathrm{~h}$. Supernatant samples were collected for analysis of glucose and SCFA consumption. Cells were collected to determine the expression of mRNA for genes associated with inflammation $(T N F$, IL1B, CXCL2, CXCL8, PTGS2, and TLR4), purinergic signaling (P2RX7, ADORAB2, and CDY3), nutrient transport [SLC16A1 (MCT1), SLC16A3 (MCT4), $S L C 5 A 8$, and $M C U$ ], and cell metabolism [ACAT1, SLC2A1 (GLUT1), IGFBP3, and IGFBP5]. Protein expression of TLR4 and ketogenic enzymes (BDH1 and HMGCS1) were also analyzed using flow cytometry. Statistical analysis was conducted with the MIXED model of SAS version 9.4 (SAS Institute Inc., Cary, $\mathrm{NC}$ ) with medium, LPS exposure, and medium $\times$ LPS interaction as fixed effects and animal within plate as a random effect. Cells tended to consume more glucose
\end{abstract}

Received June 14, 2020.

Accepted August 11, 2020.

*Corresponding author: greg.penner@usask.ca when exposed to LPS as opposed to no LPS exposure (31.8 vs. $28.7 \pm 2.7$ ), but consumption of propionate and butyrate was not influenced by LPS. Expression of $T N F$ and $I L 1 B$ was upregulated when exposed to LPS, and expression of CXCL2 and CXCL8 increased following LPS exposure with SCFA (medium $\times$ LPS). For cells exposed to LPS, we found a downregulation of $A C A T 1$ and IGFBP5 and an upregulation of SLC2A1, $S L C 16 A 3, M C U$, and IGFBP3. Medium with SCFA led to greater expression of $M C U$. SLC16A1 was upregulated in cells incubated with SCFA and without LPS compared with the other groups. Protein expression of ketogenic enzymes was not affected; however, BDH1 mean fluorescence intensity (MFI) expression tended to be less in cells exposed to LPS. These data are interpreted to indicate that when REC are exposed to LPS, they may increase glucose metabolism. Moreover, transport of solutes was affected by SCFA in the medium and by exposure to LPS. Overall, the results suggest that metabolic function of REC in vitro is altered by a proinflammatory response, which may lead to a greater glucose requirement.

Key words: cell culture, inflammation, metabolism

\section{INTRODUCTION}

The rumen is uniquely designed for efficient uptake and metabolism of nutrients, especially for shortchain fatty acids. These functions are facilitated by the ruminal epithelium, which comprises stratified squamous epithelial cells, organized into the stratum corneum, granulosum, spinosum, and basale (Graham and Simmons, 2005). The highly specialized cells of the spinosum and basale strata are responsible for transcellular transport and metabolism of large quantities of short-chain fatty acids (Stumpff, 2018), and short-chain fatty acids serve as a primary substrate for whole-body energy supply but are also important energy substrates for the cells (Britton and Krehbiel, 1993; Sehested et al., 1999).

Ruminal acidosis, a potential consequence of feeding highly fermentable diets, leads to an increase in the concentration of microbe-associated molecular patterns 
(MAMP) in ruminal fluid, of which LPS has been the most widely studied (Plaizier et al., 2012). Previous work has provided evidence that acidotic conditions can lead to translocation of bacteria or MAMP across the ruminal epithelium. These conditions are thought to play a causative role in the induction of liver abscesses, laminitis, and systemic inflammation, and may negatively affect production, whether milk yield (Khafipour et al., 2009; Plaizier et al., 2012) or growth and feed conversion (Castillo-Lopez et al., 2014). In addition, ruminal MAMP may be capable of interacting with ruminal epithelial cells (REC) and initiating a local inflammatory response (Plaizier et al., 2018; Kent-Dennis et al., 2019).

At a whole-body level, inflammation markedly increases glucose (Kvidera et al., 2017) and amino acid cost (McNeil et al., 2016) in ruminants. Although the liver is a central organ that is involved, localized proinflammatory responses have been shown to alter nutrient transport and metabolic function in intestinal mucosa (Peuhkuri et al., 2010; Glover and Colgan, 2011). Inflammation in the intestinal epithelium not only results in increased permeability but also impairs proton-coupled nutrient transport (Thibault et al., 2007). Moreover, in experimental colitis models, butyrate oxidation by colonocytes was decreased and secretion of ketone bodies reduced (Ahmad et al., 2000). Pathologies of the intestinal mucosa, such as inflammatory bowel diseases, have also been reported to increase demands for oxygen and energy substrates, especially glucose, in inflamed mucosa (Glover and Colgan, 2011). Metabolic function of keratinocytes, which bear many similarities to REC, may also be altered by inflammation of the skin (Zhang et al., 2018). The increased energy costs during inflammation have been attributed to an increase in cell proliferation, especially for leukocytes, as well as to increased production of immune-modulatory molecules such as cytokines, which have additional regulatory effects on metabolism (Richardson and Davidson, 2003).

Acidotic conditions in the rumen driving a local inflammatory response in the ruminal epithelium have been speculated to alter metabolic function of the REC (Steele et al., 2011; Zhao et al., 2017). However, little direct evidence exists of the effects of inflammation on REC metabolism. Because substantial metabolism of energy substrates occurs in the REC (Britton and Krehbiel, 1993; Penner et al., 2011), it could be speculated that initiation of a proinflammatory response to ruminally-derived MAMP may alter nutrient transport and cell metabolic function. In addition, short-chain fatty acids, especially butyrate, are known to have protective or anti-inflammatory functions in intestinal epithelial cells when exposed to LPS or during active inflammation (Corrêa-Oliveira et al., 2016; Parada et al., 2019). These functions have not been well characterized in the ruminal epithelium (Zhan et al., 2019). In this experiment, we hypothesized that primary REC would increase utilization of energy substrates when exposed to LPS. In addition, adding butyrate and propionate to the culture medium would have a protective effect, resulting in a suppressed proinflammatory response. Therefore, the aim of this study was to investigate the effects of LPS on nutrient transport and metabolic function of primary REC in culture, as well as to understand how SCFA affect the proinflammatory response, by evaluating energy substrate consumption and by analyzing the expression of genes and proteins involved in inflammation and metabolism.

\section{MATERIALS AND METHODS}

This study was preapproved by the University of Saskatchewan (Saskatoon, SK, Canada) Research Ethics Board (protocol no. 20100021) and was conducted in accordance with guidelines of the Canadian Council of Animal Care (Ottawa, ON, Canada).

\section{Rumen Epithelial Cell Isolation and Cultivation}

Yearling beef heifers $(n=9)$ were housed in individual pens for $28 \mathrm{~d}$ and fed a diet of $40.00 \%$ barley silage, $10.00 \%$ grass hay, $33.22 \%$ dry-rolled barley, $16.44 \%$ vitamin and mineral pellet, and $0.34 \%$ limestone on a DM basis. Heifers were allowed ad libitum water consumption. On d 28, heifers were euthanized by captive bolt, followed by exsanguination and pithing. Heifers were staggered such that only 1 animal per day was euthanized for sample collection. Ruminal epithelial tissue was excised from the ventral sac and was subsequently washed and transported to the laboratory in ice-cold $\mathrm{Ca}^{2+}$ - and $\mathrm{Mg}^{2+}$-free Dulbecco's phosphate-buffered saline (DPBS; Sigma-Aldrich, St. Louis, MO) containing antibiotic-antimycotic (antianti; final concentration: $400 \mathrm{U} / \mathrm{mL}$ penicillin, 400 $\mu \mathrm{g} / \mathrm{mL}$ streptomycin, and $1 \mu \mathrm{g} / \mathrm{mL}$ amphoteracin $\mathrm{B}$; Thermo Fisher Scientific, Waltham, MA) and nystatin (240 U/mL; Sigma-Aldrich). Ruminal papillae were cut off at the base, washed in DPBS solution containing anti-anti (final concentration: $100 \mathrm{U} / \mathrm{mL}$ penicillin, 100 $\mu \mathrm{g} / \mathrm{mL}$ streptomycin, and $0.25 \mu \mathrm{g} / \mathrm{mL}$ amphoteracin B; Thermo Fisher), and approximately $30 \mathrm{~g}$ (initial wet weight) of tissue was subjected to serial trypsinization with $50 \mathrm{~mL}$ of a trypsin-EDTA solution (0.25\% trypsin and $0.02 \%$ EDTA; Sigma-Aldrich) at $37^{\circ} \mathrm{C}$. Fresh trypsin-EDTA solution was replaced every $30 \mathrm{~min}$. The first 2 fractions of supernatant contained highly keratinized cells and were discarded. The subsequent 4 fractions were each strained through sterile gauze and 
centrifuged for 5 min at $200 \times g$ at room temperature. The resulting cell pellet was washed and centrifuged 3 times with sterile DPBS containing $\mathrm{Ca}^{2+}$ and $\mathrm{Mg}^{2+}$. Pellets from the 4 fractions were pooled, resuspended, and seeded into $60-\mathrm{mm}$ cell culture plates that were precoated with bovine collagen I (Thermo Fisher). Cells were grown in M199 cell culture medium (M2154; Sigma-Aldrich) with the addition of fetal bovine serum (15\% vol/vol; Thermo Fisher), L-glutamine (1.36 $\mathrm{mM}$; Sigma-Aldrich), HEPES (20 mM; Sigma-Aldrich), antianti (final concentration: $100 \mathrm{U} / \mathrm{mL}$ penicillin, $100 \mu \mathrm{g} /$ $\mathrm{mL}$ streptomycin, and $0.25 \mu \mathrm{g} / \mathrm{mL}$ amphoteracin $\mathrm{B}$; Thermo Fisher), nystatin (240 U/mL; Sigma-Aldrich), gentamycin $(50 \mathrm{mg} / \mathrm{L}$; Sigma-Aldrich), and kanamycin (100 mg/L; Thermo Fisher) for $2 \mathrm{~d}$, and then the medium was switched to minimum essential medium (MEM) with stable L-glutamine (M4655; SigmaAldrich) with the addition of fetal bovine serum (10\% vol/vol; Thermo Fisher), HEPES (20 mM; Sigma), and anti-anti (final concentration: $100 \mathrm{U} / \mathrm{mL}$ penicillin, 100 $\mu \mathrm{g} / \mathrm{mL}$ streptomycin, and $0.25 \mu \mathrm{g} / \mathrm{mL}$ amphoteracin B; Thermo Fisher). Fresh medium was replaced every 2 to $3 \mathrm{~d}$, and cells were cultured for 10 to $12 \mathrm{~d}$ until 80 to $90 \%$ confluency was attained. An anti-CD90 antibody (final concentration: $0.02 \mathrm{mg} / \mathrm{mL}$; Novus Biologicals, Centennial, CO) was used to determine fibroblast contamination (Kent-Dennis et al., 2020). Cells that were $<10 \%$ positive for CD90 were considered acceptable for experimentation (Kisselbach et al., 2009). Cells from each animal were then reseeded into two 24 -well culture plates (Thermo Fisher) at a rate of $10 \times 10^{4}$ cells $/ \mathrm{mL}$ and used for the experiment.

\section{Experimental Procedure}

The day of reseeding was considered d 0 of the experiment (Figure 1). The total experiment for each batch of REC was conducted over a duration of $5 \mathrm{~d}$. Cells were reseeded in unaltered MEM (REG). On day 2 , fresh medium was added to the wells with 1 plate per animal receiving REG and the other plate receiving MEM with Na-butyrate and Na-propionate $(2 \mathrm{mM}$ and $5 \mathrm{~m} M$ final concentrations, respectively; SCFA). The concentration of butyrate selected was expected to be sufficient to influence cell functions without causing cytotoxic effects (Gálfi et al., 1991), and the propionate concentration was selected to maintain the butyrateto-propionate ratio based on Klotz et al. (2001). On d 4, fresh REG and SCFA were added to the respective wells. Subsamples of each medium source, before addition to the cells, were collected and frozen at $-20^{\circ} \mathrm{C}$. On d 4, cells were exposed to the treatments, which were arranged in a $2 \times 2$ factorial, with a total of 4 wells per treatment. Cells were incubated in REG or SCFA and with or without LPS $(50,000 \mathrm{EU} / \mathrm{mL} ;$ Escherichia coli 055:B5, Sigma-Aldrich), resulting in the following treatment groups: REG without LPS (control; REG-LPS); REG with LPS added (REG+LPS); SCFA without LPS (SCFA-LPS); and SCFA with LPS added (SCFA+LPS). The experiment ended $24 \mathrm{~h}$ later, on d 5. Supernatant from each well was collected and frozen at $-20^{\circ} \mathrm{C}$. Cells from 2 wells per treatment were collected by trypsinization for immediate analysis of TLR4, BDH1, and HMGCS1 staining by flow cytometry. The cell lysate from 2 wells per treatment was also collected and pooled in $1 \mathrm{~mL}$ of Trizol (Thermo Fisher). Samples were frozen at $-80^{\circ} \mathrm{C}$ for later RNA extraction.

\section{Analysis of Supernatants}

Glucose Consumption. Glucose concentrations in the media and supernatants were quantified using an enzymatic assay modified from that used to assess

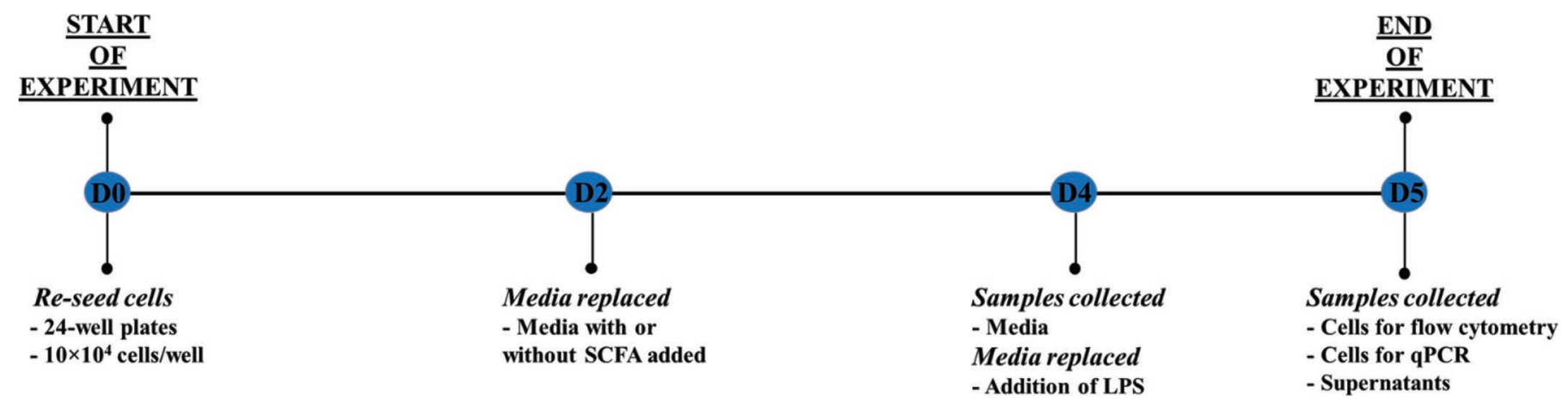

Figure 1. Timeline of treatments and sample collections of cultured ruminal epithelial cells. Cells were grown with or without short-chain fatty acids (SCFA; $2 \mathrm{mM}$ butyrate and $5 \mathrm{mM}$ propionate) added to the medium starting on d 2 (D2) following reseeding. Cells were incubated with LPS for $24 \mathrm{~h}$ starting on d 4. 
glucose concentration in plasma. The reaction utilized a peroxidase-glucose oxidase enzyme solution (SigmaAldrich) and o-dianisidine (Sigma-Aldrich) as the substrate. Absorbance was determined using a plate reader (Epoch2; BioTek Instruments, Winooski, VT) at a wavelength of $450 \mathrm{~nm}$. Glucose consumption (disappearance) was calculated based on the differences in concentration between the fresh medium and supernatant and the volume of the medium and supernatant.

Butyrate and Propionate Consumption. Concentrations of butyrate and propionate in the media and supernatants were determined as described by Khorasani et al. (1996) using gas chromatography (Agilent Technologies, Santa Clara, CA) equipped with a Zebron capillary column (ZB-FFAP; $30-\mathrm{m} \times 0.32-\mathrm{mm}$ inner diameter $\times 0.25-\mu \mathrm{m}$ film thickness; Phenomenex, Torrence, CA) with minor modifications. For detection of SCFA in cell culture media, a 1:5 split ratio was used with a $1-\mu \mathrm{L}$ injection volume. The injector temperature was $225^{\circ} \mathrm{C}$. The oven temperature was initially ramped up to $90^{\circ} \mathrm{C}$ and then increased to $170^{\circ} \mathrm{C}$ at a rate of $10^{\circ} \mathrm{C} / \mathrm{min}$, where the temperature was held for $2 \mathrm{~min}$. The detector temperature was held constant at $250^{\circ} \mathrm{C}$. Isocaproic acid was used as the internal standard. Consumption (disappearance) of butyrate and propionate by the cells was determined by calculating the difference between concentrations in the medium and the supernatant and corrected to account for well volume and time, as described for glucose.

\section{Cell Staining and Flow Cytometry}

Expression of TLR4, BDH1, and HMGCS1, as well as the percent of dead and apoptotic cells, were analyzed using flow cytometry. The staining and analysis were performed as described by Käser et al. (2016). Singlemarker staining was conducted using the antibodies detailed in Table 1. Following trypsinization, cells were resuspended in $5 \mathrm{~mL}$ of medium to neutralize the trypsin and centrifuged at $200 \times g$ for $5 \mathrm{~min}$ at room temperature, and then the supernatant was decanted. Cells were incubated in 96-well round-bottom plates (Thermo Fisher) for $1 \mathrm{~h}$ at $4^{\circ} \mathrm{C}$ in fixation/permeabilization reagent (3:1 ratio of diluent to concentrate) from the FoxP3/Transcription Factor Staining Buffer Kit (eBioscience, San Diego, CA). Plates were then centrifuged at $500 \times g$ at room temperature, and the supernatant was removed. Cells were blocked with fetal bovine serum (neat) for $15 \mathrm{~min}$ at room temperature. Plates were centrifuged again, the supernatant was removed, and cells were incubated with $10 \mu \mathrm{L}$ of primary antibody for $10 \mathrm{~min}$ at room temperature. Plates were washed twice with $200 \mu \mathrm{L}$ of permeabilization buffer provided with the kit (diluted 1:10 with water) and centrifuged, and the supernatant was removed. Cells were then incubated with $10 \mu \mathrm{L}$ of secondary antibody for 10 min without light exposure at room temperature. Plates were washed twice, using the same method described above. After the last wash, the cells were resuspended in $200 \mu \mathrm{L}$ permeabilization buffer, transferred to a 2-mL microcentrifuge tube (Thermo Fisher), and analyzed using an Accuri C6 flow cytometer (BD Biosciences, Franklin Lakes, NJ) based on a minimum of 5,000 events. The absence of nonspecific binding was evaluated using isotype controls. Data analysis of percent positive and mean fluorescence intensity (MFI) were performed using FlowJo Software (BD Biosciences).

A subset of samples $(\mathrm{n}=3)$ were used to monitor the effect of the treatments on apoptosis and cell death by staining cells with annexin and propidium iodide markers, respectively (Annexin V-FITC Apoptosis Kit Plus, Biovision Inc., Milpitas, CA). Following trypsinization, cells were resuspended in $100 \mu \mathrm{L}$ of binding buffer, provided with the kit, and $1 \mu \mathrm{L}$ each of annexin and propidium iodide was added to the cell suspension. Cells were incubated with the markers for $10 \mathrm{~min}$ in the dark at room temperature and then analyzed with the flow cytometer. Each marker was incubated and analyzed in separate tubes.

Table 1. Description of antibodies used to evaluate inflammatory and metabolic effects of LPS exposure on cultured ruminal epithelial cells

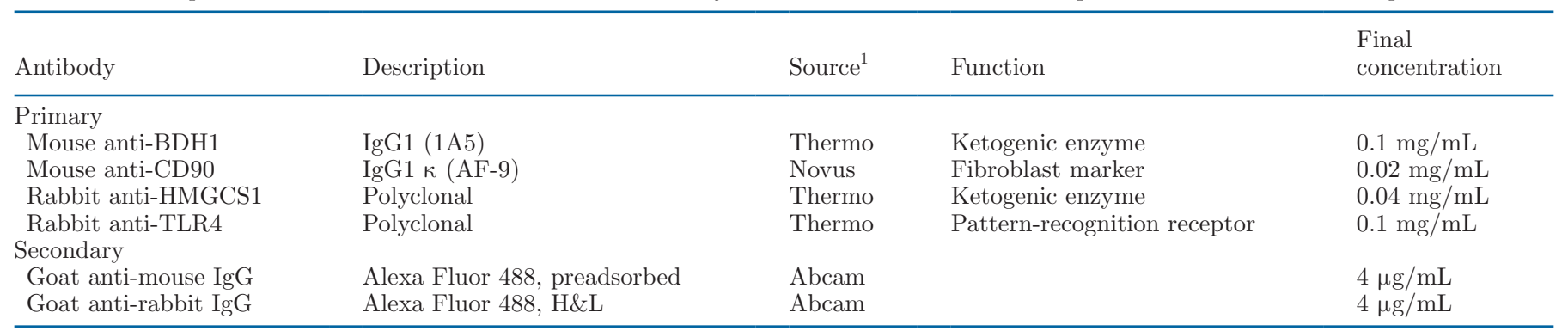

\footnotetext{
${ }^{1}$ Thermo Fisher Scientific, Waltham, MA; Novus Biologicals, Centennial, CO; Abcam, Cambridge, UK.
} 


\section{RNA Extraction and Real-Time Quantitative PCR}

Samples of cell lysate, in Trizol, were thawed, and a phenol-chloroform RNA extraction (Thermo Fisher) was used with 2 precipitation steps using isopropanol following phase separation. Linear acrylamide (Thermo Fisher) was used as a co-precipitant (final concentration of $15 \mu \mathrm{g} / \mathrm{mL}$ ) to visualize the pellet. The concentration of RNA was determined using a Nanodrop (ND2000c; Thermo Fisher). A $1.2 \%$ denaturing agarose gel was used to determine RNA integrity. The presence of distinct $18 \mathrm{~s}$ and $28 \mathrm{~s}$ bands in all samples was confirmed before RNA was used. Subsequently, $2 \mu \mathrm{g}$ of RNA was converted to cDNA using the High-Capacity Reverse Transcription Kit (Thermo Fisher). The cDNA was diluted with nuclease-free water to a final concentration of $10 \mathrm{ng} / \mathrm{uL}$.

Primer pairs for reference and target genes were obtained from Integrated DNA Technologies (Coralville, IA) and are listed in Table 2. Primers were designed to span exon-exon junctions, where possible, and were assessed for efficiency [calculated as $-1+10(-1 /$ slope $)$ $\times 100$ ] using a serial dilution of pooled cDNA. Melt curves for primers were assessed for dimer formation to verify the presence of a single product.

Quantitative real-time PCR was performed using 20 ng of cDNA, run in duplicate, using SsoFast EvaGreen Supermix (Bio-Rad, Hercules, CA) on a CFX96 RealTime PCR Detection System (Bio-Rad). The Ct values for the target genes were normalized to the geometric mean of the 3 reference genes $(A C T B, G A P D H$, and $S T X 5)$, and statistical analysis was performed on $\Delta \mathrm{Ct}$. Data are presented as fold changes, with treatments held relative to the mean value of REG-LPS.

\section{Statistical Analysis}

Data were analyzed using the MIXED procedure of SAS 9.4 (SAS Institute, Cary, NC) with LPS treatment, medium, and treatment $\times$ medium interaction as fixed effects. Animal within plate was considered random. Data were analyzed using mean separations. Differences were considered significant at $P<0.05$.

\section{RESULTS}

\section{Glucose and SCFA Concentrations in Cell Supernatants}

The percent of glucose (Table 3 ) consumed by REC incubated with SCFA was $13.9 \%$, compared with $46.6 \%$ when incubated with REG (SEM $=3.7 ; P<0.001$ ). Cells exposed to LPS tended to consume more glucose than those in medium without LPS (31.8 vs. $28.7 \pm 2.7$;
$P=0.072$ ), but the amount of butyrate and propionate consumed was not affected by LPS exposure. Collectively, cells incubated with SCFA consumed $0.42 \mathrm{mmol}$ $(21.2 \%)$ of the butyrate and $0.38 \mathrm{mmol}(7.6 \%)$ of the propionate (Table 3 ).

\section{Cell Staining}

The MFI for TLR4, BDH1, and HMGCS1 (Table 4) were not affected by medium or LPS treatment, and no interactions were detected. However, we detected a tendency for MFI of BDH1 to be less in cells exposed to LPS $(P=0.076)$. Compared with REG, exposure to SCFA resulted in a reduced number of cells positive for TLR4 (94.8 vs. $87.0 \pm 2.5 \% ; P=0.046)$ and BDH1 (83.4 vs. $66.4 \pm 4.6 \% ; P=0.020$ ), but HMGCS1 was not affected. Cell death (propidium iodide) and apoptosis (annexin) were not affected by SCFA or LPS exposure (Table 4).

\section{Gene Expression}

Expression of TNF (Figure 2A) and IL1B (Figure $2 \mathrm{~B})$ was greater $(P<0.001)$ following LPS exposure. Addition of SCFA to the medium also resulted in greater expression of TNF and IL1B compared with REG ( $P$ $<0.001)$. Compared with REG-LPS, REG+LPS and SCFA-LPS increased expression of both CXCL2 (Figure 2C) and $C X C L 8$ (Figure 2D), and greatest expression of CXCL2 and CXCL8 occurred in cells exposed to LPS with SCFA in the medium (LPS $\times$ medium, $P<$ 0.001). A tendency for the same response also occurred for TNF (LPS $\times$ medium, $P=0.068$ ). Exposure to LPS resulted in increased expression of PTGS2 (Figure 3A; $P<0.001$ ); however, PTGS2 expression was not influenced by SCFA. Expression of TLR4 (Figure 3B) also increased with LPS exposure $(P<0.001)$; however, SCFA added to the medium downregulated TLR 4 $(P=0.008)$. Neither LPS nor SCFA influenced TGFB1 (Figure 3C).

A significant treatment $\times$ medium interaction occurred, such that expression of P2RX7 (Figure 4A) was less for cells exposed to LPS in REG $(P=0.006)$ compared with the other treatments. Exposure to LPS increased expression of ADORA2B (Figure 4B; $P<$ 0.001 ) and decreased expression of $C D 73$ (Figure $4 \mathrm{C}$; $P=0.002$ ).

Although HIF1A (Figure 5A) was not affected by LPS or medium, SCFA-LPS had decreased expression of GLUT1 compared with REG+LPS and SCFA+LPS (Figure 5B; treatment $\times$ medium $P=0.010$ ). A treatment $\times$ medium interaction resulted in an upregulation of MCT1 (Figure $6 \mathrm{~A}$; treatment $\times$ medium $P=$ 0.001) when SCFA was added to the medium without 


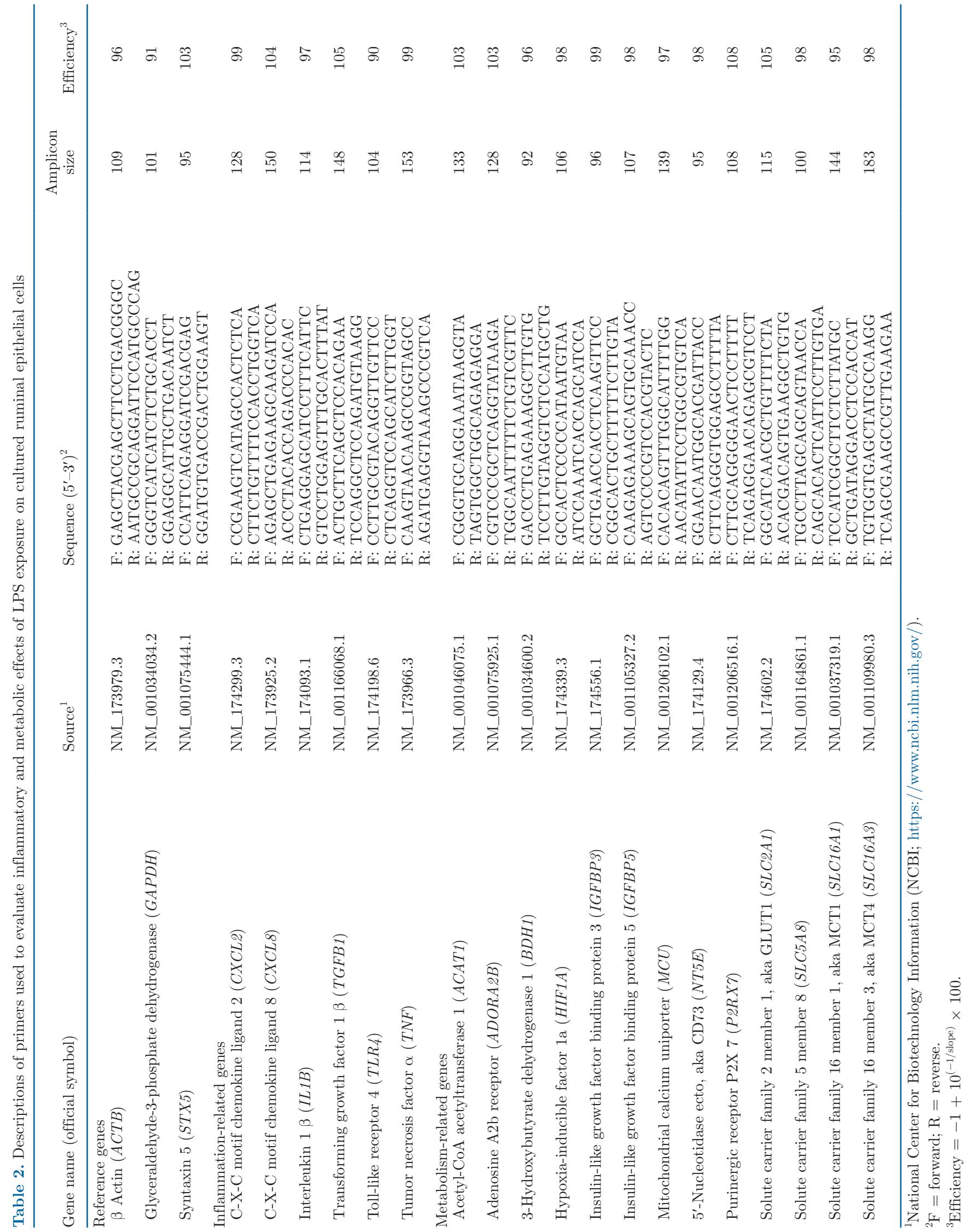


Table 3. Percent consumption ${ }^{1}$ of energy substrates in primary ruminal epithelial cells exposed to 0 ( - LPS) or 50,000 EU/mL LPS (+LPS), with or without the addition of SCFA to the culture medium

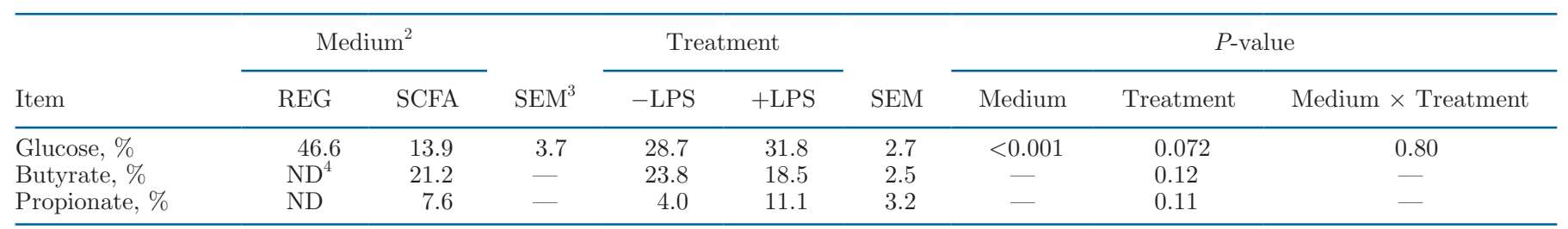

${ }^{1}$ Calculated by subtracting the amount measured in the supernatants from the amount measured in medium subsamples before use.

${ }^{2} \mathrm{REG}=$ regular (unaltered) culture medium; SCFA $=$ medium supplemented with $2 \mathrm{~m} M$ butyrate and $5 \mathrm{~m} M$ propionate.

${ }^{3} \mathrm{SEM}=$ standard error of the mean of each factor.

${ }^{4} \mathrm{ND}=$ not detected.

LPS exposure. Expression of MCT4 (Figure 6B) and $S L C 5 A 8$ (Figure $6 \mathrm{C}$ ) were greater $(P=0.031$ and $P=$ 0.004, respectively) following LPS exposure compared with cells incubated without LPS. Exposure to LPS did not affect $M C U$ expression (Figure 6D); however, the addition of SCFA increased expression $(P=0.002)$.

Downregulation of ACAT1 (Figure 7A; $P<0.001$ ) and $B D H 1$ (Figure 7B; $P=0.001$ ) occurred following exposure to LPS. However, BDH1 increased in expression $(P=0.046)$ when SCFA were added to the medium. This also tended to be the case for ACAT1 ( $P$ $=0.072$ ). Both LPS and SCFA increased expression of IGFBP3 (Figure 7C; $P=0.001$ and $P<0.001$, respectively), and exposure to LPS resulted in a downregulation of IGFBP5 (Figure 7D; $P<0.001$ ). For IGFBP5 tendency for a treatment $\times$ medium interaction $(P=$ 0.050) was detectable.

\section{DISCUSSION}

A proinflammatory response at a mucosal surface is initiated, whether by immune cells or nonhemopoietic cell types, by the binding of MAMP to pattern-recognition receptors, activating a signaling cascade that leads to transcription of cytokines, chemokines, and other immune-modulatory molecules (Pott and Hornef, 2012). Recent work has suggested that REC are capable of initiating a proinflammatory response (Zhang et al., 2016; Kent-Dennis et al., 2020). In addition to epithelial cells, large numbers of immune cells, such as neutrophils, macrophages, and lymphocytes, are recruited to the site of the insult and further promote inflammation to eliminate the threat, repair cellular damage, and return the tissue to a homeostatic state (Peterson and Artis, 2014). As a consequence, meta-

Table 4. Percent positive and mean fluorescence intensity for markers in primary ruminal epithelial cells exposed to 0 ( - LPS) or 50,000 EU/ mL LPS (+LPS)

\begin{tabular}{|c|c|c|c|c|c|c|c|c|c|}
\hline \multirow[b]{2}{*}{ Item } & \multicolumn{2}{|c|}{ Medium $^{1}$} & \multirow[b]{2}{*}{$\mathrm{SEM}^{2}$} & \multicolumn{2}{|c|}{ Treatment } & \multirow[b]{2}{*}{ SEM } & \multicolumn{3}{|c|}{$P$-value } \\
\hline & REG & SCFA & & $-\mathrm{LPS}$ & $+\mathrm{LPS}$ & & Medium & Treatment & $\begin{aligned} & \text { Medium } \\
\times & \text { Treatment }\end{aligned}$ \\
\hline \% Positive & 94.8 & 87.0 & 2.5 & 90.8 & 91.0 & 2.7 & 0.046 & 0.82 & 0.60 \\
\hline $\mathrm{MFI}^{3}$ & 87,794 & 94,273 & 12,953 & 89,856 & 92,211 & $9,299.2$ & 0.73 & 0.47 & 0.51 \\
\hline BDH1 & & & & & & & & & \\
\hline \multicolumn{10}{|l|}{ HMGCS1 } \\
\hline \% Positive & 66.0 & 47.9 & 7.4 & 56.4 & 57.5 & 5.5 & 0.101 & 0.72 & 0.88 \\
\hline MFI & 33,872 & 34,002 & $5,331.6$ & 32,744 & 35,129 & $3,961.0$ & 0.99 & 0.33 & 0.62 \\
\hline Annexin ${ }^{4}$ & & & & & & & & & \\
\hline \% Positive & 9.5 & 10.8 & 4.7 & 10.1 & 10.2 & 3.4 & 0.85 & 0.93 & 0.73 \\
\hline $\begin{array}{l}\text { Propidium iodide } \\
\% \text { Positive }\end{array}$ & 8.0 & 7.3 & 3.8 & 7.4 & 7.9 & 2.7 & 0.91 & 0.38 & 0.54 \\
\hline
\end{tabular}

${ }^{1} \mathrm{REG}=$ regular (unaltered) medium, SCFA $=$ medium with $2 \mathrm{~m} M$ butyrate and $5 \mathrm{~m} M$ propionate added.

${ }^{2} \mathrm{SEM}=$ standard error of the mean of each factor.

${ }^{3}$ Mean fluorescence intensity, arbitrary unit.

${ }^{4}$ Marker indicative of apoptotic cells.

${ }^{5}$ Marker indicative of dead cells. 
A TNF

Treatment: $P<0.001$

Medium: $P=0.006$

Treatment $\times$ Medium: $P=0.068$

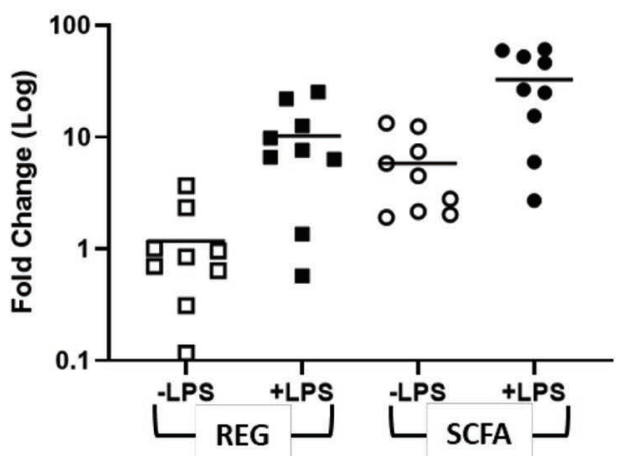

C CXCL2

Treatment: $P<0.001$

Medium: $P<0.01$

Treatment $\times$ Medium: $P<0.001$

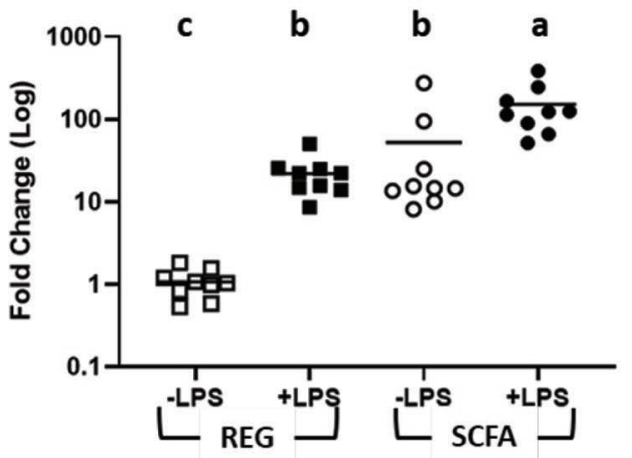

B IL1B

Treatment: $P<0.001$

Medium: $P<0.001$

Treatment $\times$ Medium: $P=0.59$

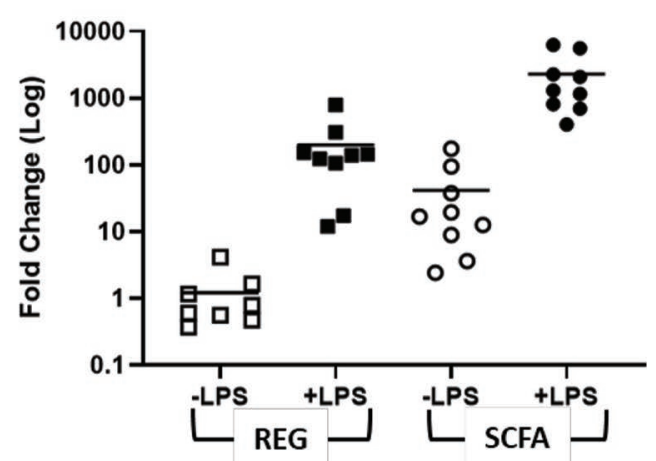

D $\mathrm{CXCL8}$

Treatment: $P<0.001$

Medium: $P<0.001$

Treatment $\times$ Medium: $P<0.001$

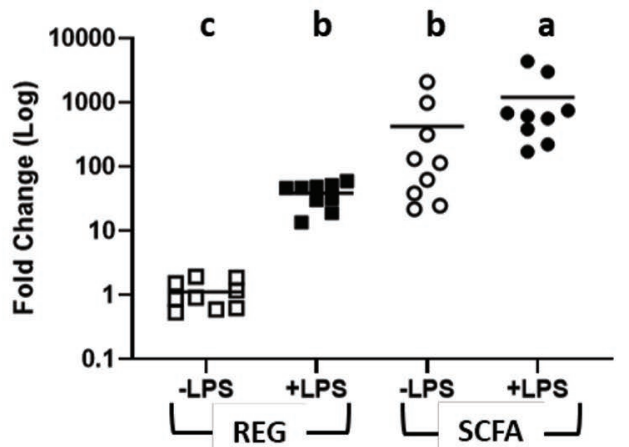

Figure 2. Gene expression of proinflammatory cytokines, TNF (A) and IL1B (B), and chemokines, CXCL2 (C) and CXCL8 (D), in cultured ruminal epithelial cells exposed to either 0 or $50,000 \mathrm{EU} / \mathrm{mL}$ LPS with (SCFA) or without (REG) the addition of short-chain fatty acids (2 m $M$ butyrate and $5 \mathrm{~m} M$ propionate) in the culture medium. The $\Delta \mathrm{Ct}$ was used for statistical analysis $(P<0.05)$, and results are presented as fold change $(\log )$, with each individual plotted. The horizontal bar represents the mean. Means with differing letters indicate significant differences $(P<0.05)$

bolic function of the tissue may be altered; however, effects of a local inflammatory response on ruminal epithelial metabolism have not been explored.

Fiber digestion in the gastrointestinal tract results in the production of short-chain fatty acids by the resident microflora. These end products of fermentation, especially butyrate, have been extensively studied, as they are important energy substrates and may also help to maintain epithelial barrier function, modify cellular processes such as proliferation, and mediate the inflammatory response in the mucosal tissue (Corrêa-Oliveira et al., 2016). In particular, the potential anti-inflammatory effects of short-chain fatty acids on intestinal epithelial cells have been of interest as a possible therapy for pathologies such as ulcerative colitis and Crohn's disease (Parada et al., 2019). However, the effects of short-chain fatty acids have been inconsistent, with both pro- and anti-inflammatory responses reported (Li et al., 2018). Addition of short-chain fatty acids to culture medium of colon epithelial cells suppressed the production of proinflammatory cytokines (Hung and Suzuki, 2018). Conversely, short-chain fatty acids have been shown to enhance expression of inflammation-induced TLR (Lin et al., 2015; Xiao et al., 2018), increase levels of proinflammatory cytokines (Vancamelbeke et al., 2019), and possibly stimulate recruitment of firstresponder cells, such as neutrophils (Corrêa-Oliveira et al., 2016). In the present study, exposure to LPS 


\section{A PTGS2}

Treatment: $P<0.001$

Medium: $P=0.28$

Treatment $\times$ Medium: $P=0.12$

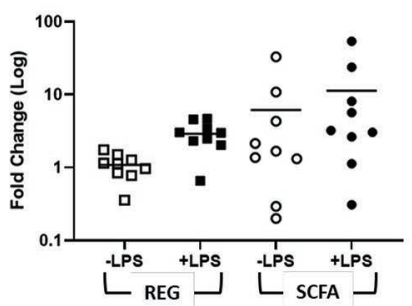

B TLR4

Treatment: $P<0.001$

Medium: $P=0.008$

Treatment $\times$ Medium: $P=0.36$

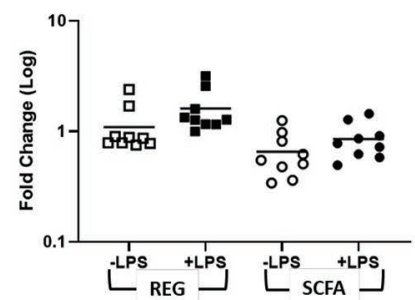

C TGFB1

Treatment: $P=0.29$

Medium: $P=0.17$

Treatment $\times$ Medium: $P=0.36$

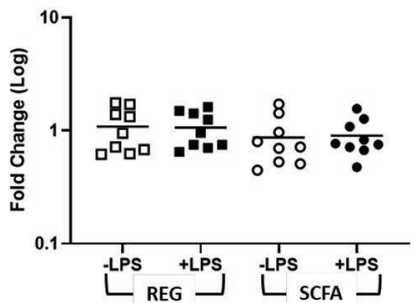

Figure 3. Gene expression of a lipid mediator of inflammation, PTGS2 (A), toll-like receptor, TLR4 (B), and growth factor-like cytokine, TGFB1 (C), in cultured ruminal epithelial cells exposed to either 0 or 50,000 EU/mL LPS with (SCFA) or without (REG) the addition of short-chain fatty acids $(2 \mathrm{mM}$ butyrate and $5 \mathrm{~m} M$ propionate) in the culture medium. The $\Delta$ Ct was used for statistical analysis $(P<0.05)$, and results are presented as fold change (log), with each individual plotted. The horizontal bar represents the mean.

and addition of SCFA to the medium independently resulted in increased expression of TLR4, TNF, and $I L 1 B$. Moreover, expression of $C X C L 2$ and $C X C L 8$, chemokines that recruit neutrophils during acute inflammation, were enhanced by the combination of LPS and SCFA. Although the reasons for the apparently paradoxical effects of short-chain fatty acids have not been elucidated, the effects observed in the present study suggest that VFA can modulate the inflammatory response to LPS in REC and may have further effects on cellular processes or metabolism. In agreement, Zhan et al. (2019) demonstrated an enhanced immune response in the presence of short-chain fatty acids in cultured REC, providing further evidence that short-chain fatty acids play a regulatory role in the inflammatory response in the ruminal epithelium.

Chemotaxis of neutrophils is intimately linked to purinergic signaling, a process that causes the release of ATP into the extracellular environment as a consequence of cellular stress, injury, or infection (Ferrari et al., 2016). The free ATP acts as a signaling molecule to fine tune immune cell responses and prevent excessive tissue damage caused by inflammation (Ferrari et al., 2016). Two main types of receptors, P2 and P1, mediate the signaling pathway. The $\mathrm{P} 2$ receptors, which are divided into the P2XR and P2YR groups, bind extracellular ATP, inducing a proinflammatory response and leading to secretion of chemokines and recruitment of immune cells (Pastore et al., 2007; Idzko et al., 2014). The ATP is then converted to AMP, facilitated by CD39. Adenosine is produced from the AMP, by the action of CD73, and binds to one of the 4 subtypes $\left(\mathrm{A}_{1}\right.$, $\mathrm{A}_{2 \mathrm{~A}}, \mathrm{~A}_{2 \mathrm{~B}}$, or $\mathrm{A}_{3}$ ) of the $\mathrm{P} 1$ receptor group (Antonioli et al., 2013). In the current study, gene expression patterns of CD73, and both a P2 (P2RX' $)$ and P1 (ADORA2B) receptor were evaluated. Following exposure to LPS, without SCFA added to the medium, REC expression of $P 2 R X 7$ was downregulated. Expression of $C D 73$ and ADORA2B (a P1 receptor), however, were upregulated in response to LPS exposure. Production of adenosine
A P2RX7

Treatment: $P=0.29$

Medium: $P=0.011$

Treatment $\times$ Medium: $P=0.006$

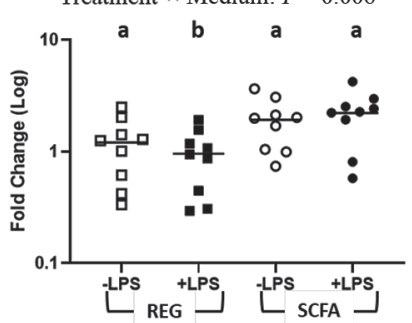

B ADORA2B

Treatment: $P<0.001$

Medium: $P=0.12$

Treatment $\times$ Medium: $P=0.45$

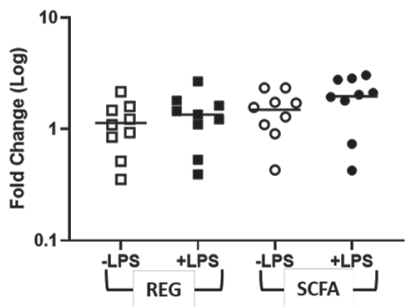

C $\mathrm{CD} 73$

Treatment: $P=0.002$

Medium: $P=0.50$

Treatment $\times$ Medium: $P=0.22$

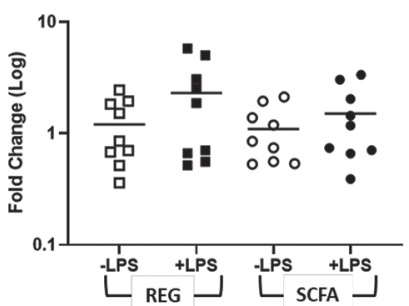

Figure 4. Gene expression of purinergic receptors, P2RX7 (A) and ADORA2B (B), and surface enzyme, CD73 (C) in cultured ruminal epithelial cells exposed to either 0 or $50,000 \mathrm{EU} / \mathrm{mL}$ LPS with (SCFA) or without (REG) the addition of short-chain fatty acids $(2 \mathrm{~m} M$ butyrate and $5 \mathrm{mM}$ propionate) in the culture medium. The $\Delta$ Ct was used for statistical analysis $(P<0.05)$, and results are presented as fold change $(\log )$, with each individual plotted. The horizontal bar represents the mean. Means with differing letters indicate significant differences $(P<$ $0.05)$. 
and binding to $\mathrm{P} 1$ receptors is associated with an antiinflammatory response (Ferrari et al., 2016). The present results are consistent with the literature, whereby activation of $\mathrm{P} 2$ and $\mathrm{P} 1$ receptors invoke opposing effects (Ferrari et al., 2016) and suggesting that the proinflammatory response in REC may be regulated to prevent cell damage.

Inflammation can result in increased catabolism and increased energy, nitrogen, and micronutrient demands (Lennie et al., 1995). Inflammation has been associated with altered metabolic activity at systemic and tissue levels (Staal-van den Brekel et al., 1995; Hardin et al., 2000). Production of immune-modulatory molecules and increases in cell turnover, both systemically and locally, are implicated in the changes in metabolic demands. Using an intravenous LPS challenge in dairy cows, Kvidera et al. (2017) demonstrated that a systemic inflammatory response increased whole-body glucose requirements. At a tissue level, an ex vivo experiment with rabbit intestinal epithelium showed that proinflammatory cytokines were associated with an increase in metabolic demands and increased glucose absorption (Hardin et al., 2000). In the present experiment, exposure to LPS increased expression of TLR4, $P T G S 2$, and cytokines $T N F$ and $I L 1 B$, suggesting the REC had initiated a proinflammatory response. Following LPS exposure, REC tended to consume more glucose, indicating that the response may have increased the energetic demand. However, the amount of butyrate and propionate consumed by the cells was not affected by LPS exposure. The increase in glucose utilization may indicate a metabolic shift toward glycolysis or oxidation. However, we did not assess lactate formation arising from glucose consumption and therefore cannot conclude whether glucose was partially metabolized or completely oxidized. Immune cells (Kominsky et al., 2010), airway epithelial cells (Garnett et al., 2016), and keratinocytes (Wickersham et al., 2017) also favor glycolysis under inflammatory conditions, suggesting that REC may do so as well.

Exposure to LPS increased the expression of GLUT1 in REC, supporting the increase in glucose consumption observed. Interestingly, the addition of SCFA, without LPS, resulted in a downregulation of GLUT1. Ability to alter the energy substrates used, depending on their availability, has previously been demonstrated in ruminal epithelial tissue (Wiese et al., 2013). These data suggest that in the presence of SCFA, a shift away from glucose utilization may occur. In addition to the function of GLUT1 in glucose transport, previous work has shown that GLUT1 may be important for modulating inflammation in the skin (Zhang et al., 2018). GLUT1 was also found to increase during inflammation-induced hypoxia, a result of depleted oxygen and increased glycolysis at sites of inflammation (Corcoran and O'Neill, 2016; Zhang et al., 2019). The present results show that GLUT1 expression in the SCFA+LPS cells was greater than without LPS, suggesting that the presence of short-chain fatty acids may promote inflammation. Others have also shown that short-chain

\section{A GLUT1}

Treatment: $P<0.001$

Medium: $P=0.085$

Treatment $\times$ Medium: $P=0.010$

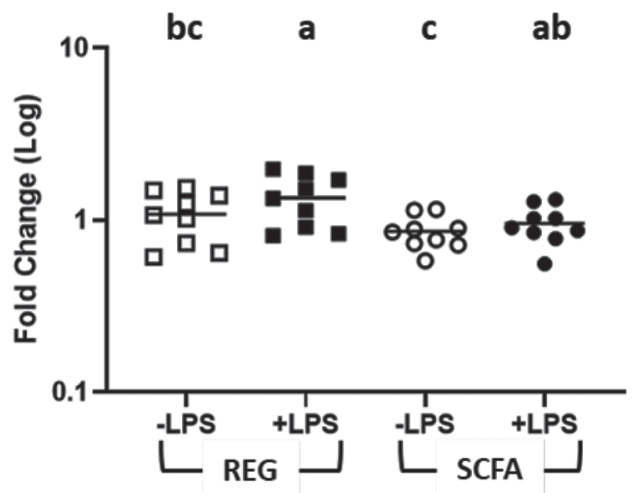

\section{B HIF1A}

Treatment: $P=0.94$

Medium: $P=0.26$

Treatment $\times$ Medium: $P=0.17$

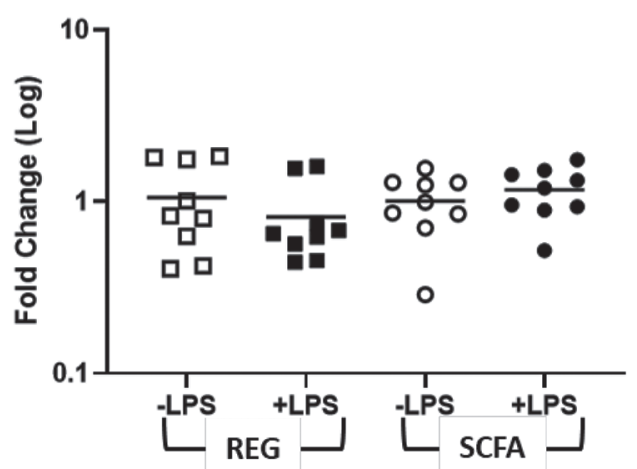

Figure 5. Gene expression of glucose transporter, GLUT1 (A), and hypoxia-inducible factor, HIF1A (B), in cultured ruminal epithelial cells exposed to either 0 or $50,000 \mathrm{EU} / \mathrm{mL}$ LPS with (SCFA) or without (REG) the addition of short-chain fatty acids ( $2 \mathrm{~m} M$ butyrate and $5 \mathrm{~m} M$ propionate) in the culture medium. The $\Delta$ Ct was used for statistical analysis $(P<0.05)$, and results are presented as fold change $($ log $)$, with each individual plotted. The horizontal bar represents the mean. Means with differing letters indicate significant differences $(P<0.05)$. 
A MCT1

Treatment: $P<0.001$

Medium: $P=0.061$

Treatment $\times$ Medium: $P=0.001$

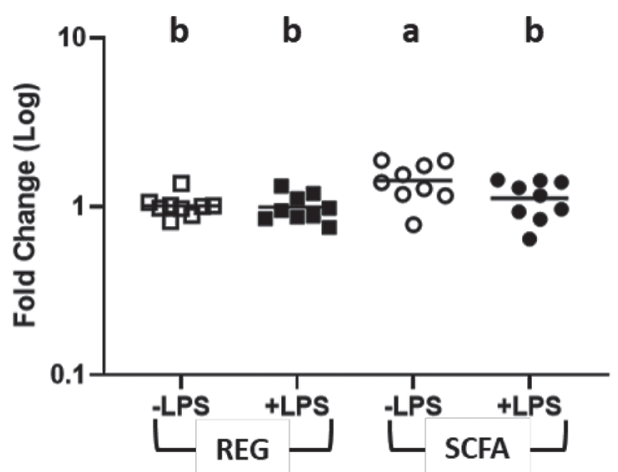

C SLC5A8

Treatment: $P=0.004$

Medium: $P=0.32$

Treatment $\times$ Medium: $P=0.76$

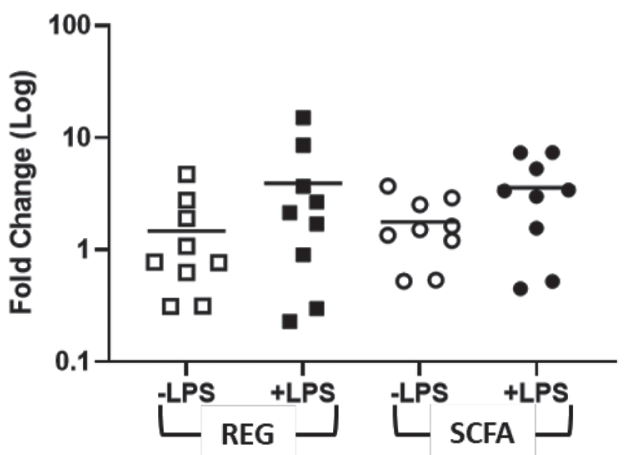

B MCT4

Treatment: $P=0.031$

Medium: $P=0.89$

Treatment $\times$ Medium: $P=0.21$

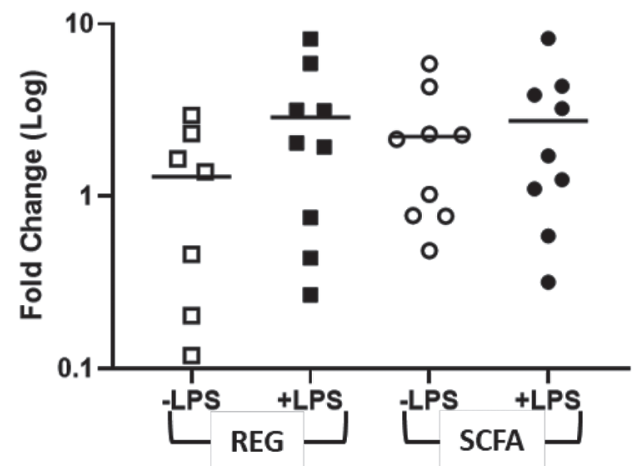

D MCU

Treatment: $P=0.58$

Medium: $P=0.002$

Treatment $\times$ Medium: $P=0.91$

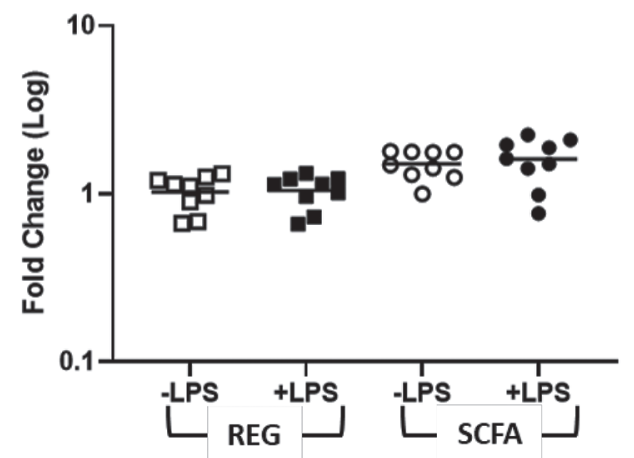

Figure 6. Gene expression of transporters, MCT1 (A) and MCT4 (B), SLC5A8 (C), and MCU (D) in cultured ruminal epithelial cells exposed to either 0 or $50,000 \mathrm{EU} / \mathrm{mL}$ LPS with (SCFA) or without (REG) the addition of short-chain fatty acids (2 m $M$ butyrate and $5 \mathrm{~m} M$ propionate) in the culture medium. The $\Delta \mathrm{Ct}$ was used for statistical analysis $(P<0.05)$, and results are presented as fold change (log), with each individual plotted. The horizontal bar represents the mean. Means with differing letters indicate significant differences $(P<0.05)$.

fatty acids have a modulating effect on REC when exposed to a variety of challenges (Meissner et al., 2017). Inflammation-induced hypoxia is mediated by HIF1A. In the present study $H I F 1 A$ was not affected by either treatment; however, HIF1A is tightly regulated, with a half-life of only a few minutes (Masoud and Li, 2015); therefore a change in mRNA expression may not have been detectable.

Expression of $I G F B P 3$ increased in response to SCFA in the medium. Insulin-like growth factor is an important homeorhetic molecule of metabolism that acts as a signal of adequate nutrient availability (Clemmons, 2012). Although tissue-dependent, previous work has shown that IGF1 increases glucose transport into non- hepatic cells (Simpson et al., 2004) and regulates utilization of nutrients such as oxidation of free fatty acids (Clemmons, 2012). In addition, IGF1 is well known for its effects on proliferation (Kiepe et al., 2005; Zheng et al., 2018). At a systemic level, IGFBP3 and IGFBP5 proteins bind to a tertiary molecule, acid-labile subunit, and together act to increase total serum IGF1 levels by prolonging its half-life (Clemmons, 2018). However, all IGF-binding proteins are pleiotropic and have local tissue-specific functions that are sometimes independent of IGF1 (Baxter, 2001; Zheng et al., 2018). Perks et al. (2000) reported that IGFBP3 and IGFBP5 have opposing functions, which was also observed in ruminal epithelial tissue by Steele et al. (2011), who 
found that a high-grain diet increased gene expression of IGFBP3, whereas IGFBP5 was downregulated. In contrast, IGFBP3 was decreased and IGFBP5 increased when butyrate was infused into the rumen in neonatal lambs (Liu et al., 2019). In the present study, $I G F B P 3$ increased with the addition of SCFA; however, $I G F B P 5$ was not affected by the medium. Previous work has suggested that butyrate, through its regulatory action on growth factors such as IGF, influences cellular proliferation and apoptosis of REC (Penner et al., 2011). Neogrády et al. (1989) indicated that butyrate may inhibit REC apoptosis in culture. However, in the present study, rates of apoptosis of REC were not influenced by SCFA in the culture medium. The mechanisms that mediate cell turnover in the ruminal epithelium in response to dietary changes involve many interconnected processes that have not been fully elucidated and warrant further investigation.

The inflammatory response has also been found to regulate the expression of IGFBP (O'Connor et al., 2008). The present results suggested that LPS increased expression of IGFBP3 but decreased IGFBP5, supporting the results of Steele et al. (2011) when imposing a rumen acidosis-induction model. Previous work has suggested that IGF may increase in response to stimulation by proinflammatory cytokines (Clemmons, 2012). However, expression of IGFBP3 is also associated with protective functions in response to
A ACAT1

Treatment: $P<0.001$

Medium: $P=0.072$

Treatment $\times$ Medium: $P=0.42$

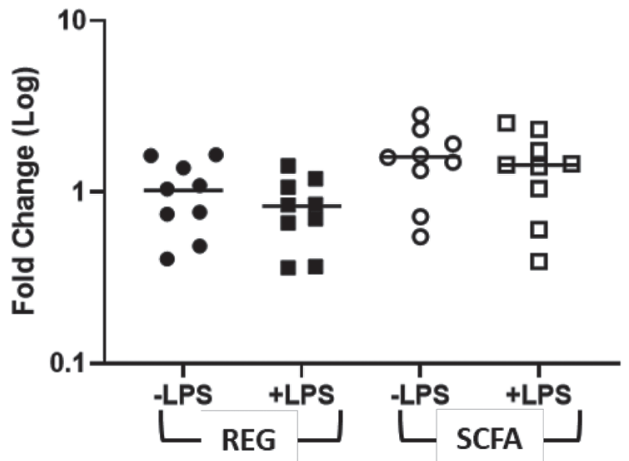

C IGFBP3

Treatment: $P=0.001$

Medium: $P=0.001$

Treatment $\times$ Medium: $P=0.34$

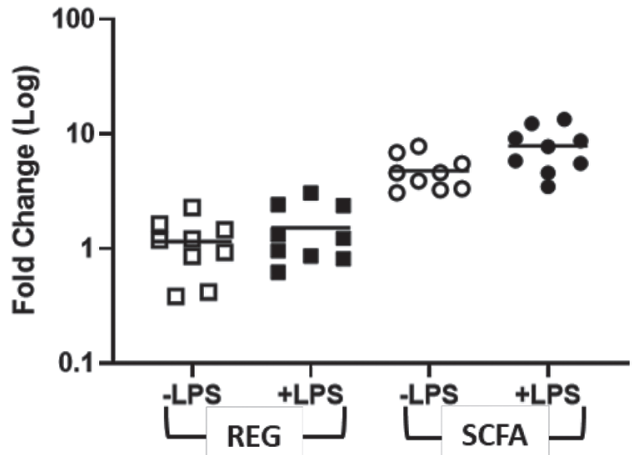

B BDH1

Treatment: $P=0.001$

Medium: $P=0.46$

Treatment $\times$ Medium: $P=0.85$

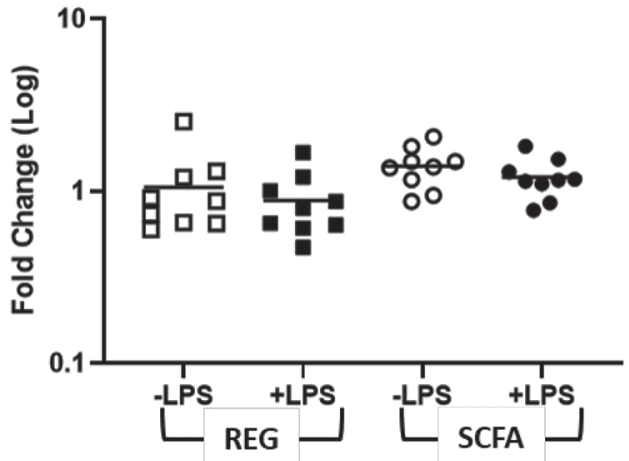

D IGFBP5

Treatment: $P<0.001$

Medium: $P=0.37$

Treatment $\times$ Medium: $P=0.050$

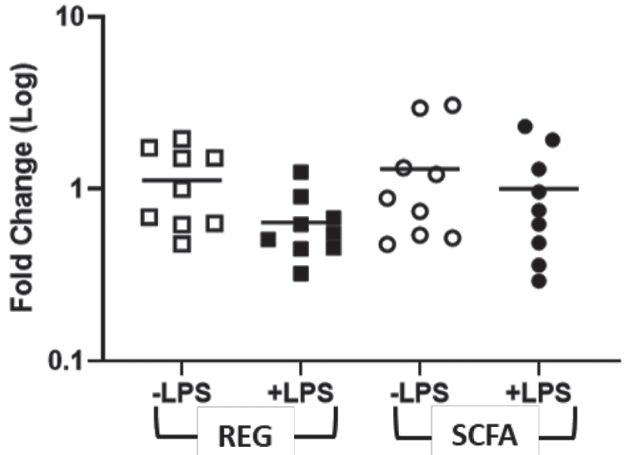

Figure 7. Gene expression of ketogenic enzymes, ACAT1 (A) and BDH1 (B), IGFBP3 (C), and IGFBP5 (D) in cultured ruminal epithelial cells exposed to either 0 or $50,000 \mathrm{EU} / \mathrm{mL}$ LPS with (SCFA) or without (REG) the addition of short-chain fatty acids $(2 \mathrm{~m} M$ butyrate and 5 $\mathrm{m} M$ propionate) in the culture medium. The $\Delta \mathrm{Ct}$ was used for statistical analysis $(P<0.05)$, and results are presented as fold change (log), with each individual plotted. The horizontal bar represents the mean. 
inflammation (O'Connor et al., 2008; Kim et al., 2018). Further research is required to elucidate the potential homeorhetic and immune-modulatory effects in REC.

As further evidence that LPS influenced metabolic activity in the present experiment, expression of ACAT1, a key mitochondrial enzyme, was downregulated in cells that had been exposed to LPS, which may suggest a shift away from ketogenesis. In the first step in the formation of ketone bodies, ACAT1 catalyzes the reaction that combines 2 acetyl-CoA molecules to form acetoacetyl-CoA and, depending on substrate availability, also catalyzes the reverse reaction. Moreover, $B D H 1$, a ketogenic enzyme that facilitates BHBA formation, was also downregulated in cells exposed to LPS. The MFI of BDH1 protein tended to be less, suggesting that, in addition to mRNA, protein expression was also affected. In agreement with the present results, Memon et al. (1992) demonstrated that LPS-induced inflammation, by way of proinflammatory cytokines $I L 1 B$ and $T N F$, resulted in reduced production of ketone bodies in mice in vivo. The inflammation-induced inhibition of ketogenesis was also observed in hepatocytes by Pailla et al. $(1998,2001)$.

A state of inflammation not only increases metabolic demands, it may also alter nutrient transport by epithelial cells (Peuhkuri et al., 2010). Previous work has demonstrated detrimental effects of experimental colitis on energy substrate uptake and metabolic function of colonocytes (Ahmad et al., 2000). Thibault et al. (2010) suggested that inflammatory bowel disease was associated with dysregulation of MCT1 and thus uptake of butyrate. In the gastrointestinal epithelia, MCT1 is an apically-localized short-chain fatty acid transporter (Graham et al., 2007), whereas MCT4 is thought to be primarily on the basolateral membrane (Kirat et al., 2007), although evidence suggests that these expression patterns may be reversed in ruminal epithelium (Stumpff, 2018). In the present study, REC not exposed to LPS had greater expression of $M C T 1$ but only in the presence of SCFA. This is in agreement with findings by Villodre Tudela et al. (2015), that MCT1 also increased following incubation with butyrate. Additionally, in the present study, expression of MCT4 and SLC5A8 were both upregulated following exposure to LPS. Increased expression of MCT4 was also observed in intestinal epithelium afflicted with inflammatory bowel disease by $\mathrm{He}$ et al. (2018). The authors suggest that MCT4 may be increased in response to greater levels of lactate. Lactate production is commonly reported in cultured cells and can indicate metabolic shifts (Hu et al., 1987; Zagari et al., 2013). Although lactate was not measured in the current experiment, the upregulation in MCT4 may have occurred in an effort to mediate lactate accumulation due to increased glycolysis. $S L C 5 A 8$, a sodium-coupled monocarboxylate transporter, is involved in the apical transport of short-chain fatty acids as well as lactate and ketone bodies (Sivaprakasam et al., 2017). Martin et al. (2006) suggested that, in addition to transport of solutes, SLC5A8 may also play a regulatory role in maintaining the energy status in some tissues.

In the REC incubated with SCFA, glucose consumption decreased compared with those incubated with REG. Although not affected by LPS treatment, the addition of SCFA to the culture medium resulted in increased expression of $M C U$, a transporter localized to the inner mitochondrial membrane that controls the influx of calcium (Paupe and Prudent, 2018). Calcium is a regulator of mitochondrial dehydrogenases and plays a key role in ATP production (Finkel et al., 2015). The increase in $M C U$ expression in REC further suggests that metabolic function was altered in culture by the presence of SCFA. Together with the expression patterns of $B D H 1, M C T 1$, and $A C A T 1$, the results suggest a shift toward butyrate metabolism in cells incubated with SCFA in culture and indicate the ability of REC to utilize short-chain fatty acids in the culture model.

\section{CONCLUSIONS}

The current study demonstrated the complexity of the inflammatory response in REC and explored how the response affected nutrient transport and metabolism. The results suggested that REC consumed more glucose following exposure to LPS, presumably as a result of the proinflammatory response. However, the difference was small, and the response did not appear to influence utilization of short-chain fatty acids added to the culture medium. Nonetheless, the results of this study suggested that the inflammatory response to LPS altered the metabolic activity of REC in culture through differential expression of genes associated with nutrient uptake. Although the exact role of short-chain fatty acids on the inflammatory response was not fully elucidated, the results of this study demonstrated evidence for regulatory roles of short-chain fatty acids in REC, especially in the recruitment of immune cells, such as neutrophils. Many questions still remain, and future research should focus on understanding the mechanisms by which the inflammatory response in REC affects nutrient transport and shifts metabolism, including the metabolic fates of glucose. Overall this study provided evidence that, although the effects on energy substrate consumption may be limited, the proinflammatory response, as a result of the interaction between ruminal epithelium and the ruminal MAMP, may bring about consequences that alter cellular processes and metabolism. 


\section{ACKNOWLEDGMENTS}

Funding support for the project was provided by the National Science and Engineering Research Council of Canada (Ottawa, ON, Canada) and the Centennial Enhancement Chair at the University of Saskatchewan (Saskatoon, SK, Canada). The authors have not stated any conflicts of interest.

\section{REFERENCES}

Ahmad, M. S., S. Krishnan, B. S. Ramakrishna, M. Mathan, A. B. Pulimood, and S. N. Murthy. 2000. Butyrate and glucose metabolism by colonocytes in experimental colitis in mice. Gut 46:493-499. https://doi.org/10.1136/gut.46.4.493.

Antonioli, L., P. Pacher, E. S. Vizi, and G. Hasko. 2013. CD39 and CD73 in immunity and inflammation. Trends Mol. Med. 19:355367. https://doi.org/10.1016/j.molmed.2013.03.005.

Baxter, R. C. 2001. Signalling pathways involved in antiproliferative effects of IGFBP-3: A review. Mol. Pathol. 54:145-148. https://doi .org $/ 10.1136 / \mathrm{mp} .54 .3 .145$.

Britton, R., and C. Krehbiel. 1993. Nutrient metabolism by gut tissues. J. Dairy Sci. 76:2125-2131. https://doi.org/10.3168/jds .S0022-0302(93)77547-5.

Castillo-Lopez, E., B. I. Wiese, S. Hendrick, J. J. McKinnon, T. A McAllister, K. A. Beauchemin, and G. B. Penner. 2014. Incidence, prevalence, severity, and risk factors for ruminal acidosis in feedlot steers during backgrounding, diet transition, and finishing. J. Anim. Sci. 92:3053-3063. https://doi.org/10.2527/jas.2014-7599.

Clemmons, D. R. 2012. Metabolic actions of insulin-like growth factor-I in normal physiology and diabetes. Endocrinol. Metab. Clin. North Am. 41:425-443. https://doi.org/10.1016/j.ecl.2012.04.017.

Clemmons, D. R. 2018. Role of IGF-binding proteins in regulating IGF responses to changes in metabolism. J. Mol. Endocrinol. 61:T139T169. https://doi.org/10.1530/JME-18-0016.

Corcoran, S. E., and L. A. O'Neill. 2016. HIF1 1 and metabolic reprogramming in inflammation. J. Clin. Invest. 126:3699-3707. https:/ /doi.org/10.1172/JCI84431.

Corrêa-Oliveira, R., J. L. Fachi, A. Vieira, F. T. Sato, and M. A Vinolo. 2016. Regulation of immune cell function by short-chain fatty acids. Clin. Transl. Immunology 5:e73. https://doi.org/10 $.1038 /$ cti.2016.17.

Ferrari, D., R. Gambari, M. Idzko, T. Muller, C. Albanesi, S. Pastore, G. La Manna, S. C. Robson, and B. Cronstein. 2016. Purinergic signaling in scarring. FASEB J. 30:3-12. https://doi.org/10.1096/ fj. $15-274563$

Finkel, T., S. Menazza, K. M. Holmstrom, R. J. Parks, J. Liu, J. Sun, J. Liu, X. Pan, and E. Murphy. 2015. The ins and outs of mitochondrial calcium. Circ. Res. 116:1810-1819. https://doi.org/10 .1161/CIRCRESAHA.116.305484.

Gálfi, P., S. Neogrády, and T. Sakata. 1991. Effects of volatile fatty acids on the epithelial cell proliferation of the digestive tract and its hormonal mediation. Pages 49-59 in T. Tsuda, Y. Sasaki, and R. Kawashima, ed. Physiological Aspects of Digestion and Metabolism in Ruminants. Academic Press, San Diego, CA.

Garnett, J. P., K. K. Kalsi, M. Sobotta, J. Bearham, G. Carr, J. Powell, M. Brodlie, C. Ward, R. Tarran, and D. L. Baines. 2016 Hyperglycaemia and Pseudomonas aeruginosa acidify cystic fibrosis airway surface liquid by elevating epithelial monocarboxylate transporter 2 dependent lactate- $\mathrm{H}^{+}$secretion. Sci. Rep. 6:37955. https://doi.org/10.1038/srep37955.

Glover, L. E., and S. P. Colgan. 2011. Hypoxia and metabolic factors that influence inflammatory bowel disease pathogenesis. Gastroenterology 140:1748-1755. https://doi.org/10.1053/j.gastro.2011 .01 .056 .

Graham, C., I. Gatherar, I. Haslam, M. Glanville, and N. L. Simmons. 2007. Expression and localization of monocarboxylate transporters and sodium/proton exchangers in bovine rumen epithelium. Am. J. Physiol. Regul. Integr. Comp. Physiol. 292:R997-R1007. https: //doi.org/10.1152/ajpregu.00343.2006.

Graham, C., and N. L. Simmons. 2005. Functional organization of the bovine rumen epithelium. Am. J. Physiol. Regul. Integr. Comp. Physiol. 288:R173-R181. https://doi.org/10.1152/ajpregu.00425 2004.

Hardin, J., K. Kroeker, B. Chung, and D. G. Gall. 2000. Effect of proinflammatory interleukins on jejunal nutrient transport. Gut 47:184-191. https://doi.org/10.1136/gut.47.2.184.

He, L., H. Wang, Y. Zhang, L. Geng. M. Yang, Z. Xu, K. Zou, W. Xu, and S. Gong. 2018. Evaluation of monocarboxylate transporter 4 in inflammatory bowel disease and its potential use as a diagnostic marker. Dis. Markers 2018:2649491. https://doi.org/10.1155/ 2018/2649491.

Hu, W. S., T. C. Dodge, K. K. Frame, and V. B. Himes. 1987. Effect of glucose on the cultivation of mammalian cells. Dev. Biol. Stand. 66:279-290.

Hung, T. V., and T. Suzuki. 2018. Short-chain fatty acids suppress inflammatory reactions in Caco-2 cells and mouse colons. J. Agric. Food Chem. 66:108-117. https://doi.org/10.1021/acs.jafc $.7 \mathrm{~b} 04233$.

Idzko, M., D. Ferrari, and H. K. Eltzschig. 2014. Nucleotide signalling during inflammation. Nature 509:310-317. https://doi.org/10 $.1038 /$ nature13085.

Käser, T., J. A. Pasternak, G. Hamonic, M. Rieder, K. Lai, M. Delgado-Ortega, V. Gerdts, and F. Meurens. 2016. Flow cytometry as an improved method for titration of Chlamydiaceae and other intracellular bacteria. Cytometry 89:451-460. https://doi.org/10 $.1002 /$ cyto.a.22822

Kent-Dennis, C., J. R. Aschenbach, P. J. Griebel, and G. B. Penner. 2020. Effects of lipopolysaccharide exposure in primary bovine ruminal epithelial cells. J. Dairy Sci. https://doi.org/10.3168/jds 2020-18652. 103:9587-9603.

Kent-Dennis, C., A. Pasternak, J. C. Plaizier, and G. B. Penner. 2019. Potential for a localized immune response by the ruminal epithelium in nonpregnant heifers following a short-term subacute ruminal acidosis challenge. J. Dairy Sci. 102:7556-7569. https://doi .org/10.3168/jds.2019-16294.

Khafipour, E., D. O. Krause, and J. C. Plaizier. 2009. A grain-based subacute ruminal acidosis challenge causes translocation of lipopolysaccharide and triggers inflammation. J. Dairy Sci. 92:10601070. https://doi.org/10.3168/jds.2008-1389.

Khorasani, G. R., G. De Boer, and J. J. Kennelly. 1996. Response of early lactation cows to ruminally undegradable protein in the diet. J. Dairy Sci. 79:446-453. https://doi.org/10.3168/jds.S0022 $-0302(96) 76384-1$

Kiepe, D., S. Ciarmatori, A. Hoeflich, E. Wolf, and B. Tonshoff. 2005. Insulin-like growth factor (IGF)-I stimulates cell proliferation and induces IGF binding protein (IGFBP)-3 and IGFBP-5 gene expression in cultured growth plate chondrocytes via distinct signaling pathways. Endocrinology 146:3096-3104. https://doi.org/10 .1210/en.2005-0324.

Kim, S. C., S. Y. Kim. H. K. Yi, and P. H. Hwang. 2018. Up-regulation of IGF binding protein-3 inhibits colonic inflammatory response. J. Korean Med. Sci. 33:e110. https://doi.org/10.3346/jkms.2018 .33.e110

Kirat, D., Y. Matsuda, N. Yamashiki, H. Hayashi, and S. Kato. 2007. Expression, cellular localization, and functional role of monocarboxylate transporter 4 (MCT4) in the gastrointestinal tract of ruminants. Gene 391:140-149. https://doi.org/10.1016/j.gene.2006 .12 .020 .

Kisselbach, L., M. Merges, A. Bossie, and A. Boyd. 2009. CD90 Expression on human primary cells and elimination of contaminating fibroblasts from cell cultures. Cytotechnology 59:31-44. https:// doi.org/10.1007/s10616-009-9190-3.

Klotz, J. L., R. L. Baldwin, R. C. Gillis, and R. N. Heitmann. 2001. Refinements in primary rumen epithelial cell incubation techniques. J. Dairy Sci. 84:183-193. https://doi.org/10.3168/jds .S0022-0302(01)74468-2. 
Kominsky, D. J., E. L. Campbell, and S. P. Colgan. 2010. Metabolic shifts in immunity and inflammation. J. Immunol. 184:4062-4068. https://doi.org/10.4049/jimmunol.0903002.

Kvidera, S. K., E. A. Horst, M. Abuajamieh, E. J. Mayorga, M. V. Fernandez, and L. H. Baumgard. 2017. Glucose requirements of an activated immune system in lactating Holstein cows. J. Dairy Sci. 100:2360-2374. https://doi.org/10.3168/jds.2016-12001.

Lennie, T. A., D. O. McCarthy, and R. E. Keesey. 1995. Body energy status and the metabolic response to acute inflammation. Am. J. Physiol. 269:R1024-R1031. https://doi.org/10.1152/ajpregu.1995 .269.5.R1024.

Li, M., B. van Esch, G. T. M. Wagenaar, J. Garssen, G. Folkerts, and P. A. J. Henricks. 2018. Pro- and anti-inflammatory effects of short chain fatty acids on immune and endothelial cells. Eur. J. Pharmacol. 831:52-59. https://doi.org/10.1016/j.ejphar.2018.05 .003 .

Lin, M. Y., M. R. de Zoete, J. P. van Putten, and K. Strijbis. 2015. Redirection of epithelial immune responses by short-chain fatty acids through inhibition of histone deacetylases. Front. Immunol. 6:554. https://doi.org/10.3389/fimmu.2015.00554.

Liu, L., D. Sun, S. Mao, W. Zhu, and J. Liu. 2019. Infusion of sodium butyrate promotes rumen papillae growth and enhances expression of genes related to rumen epithelial VFA uptake and metabolism in neonatal twin lambs. J. Anim. Sci. 97:909-921. https://doi.org/ $10.1093 /$ jas/sky459.

Martin, P. M., E. Gopal, S. Ananth, L. Zhuang, S. Itagaki, B. M. Prasad, S. B. Smith, P. D. Prasad, and V. Ganapathy. 2006. Identity of SMCT1 (SLC5A8) as a neuron-specific $\mathrm{Na}^{+}$-coupled transporter for active uptake of L-lactate and ketone bodies in the brain. J. Neurochem. 98:279-288. https://doi.org/10.1111/j.1471 $-4159.2006 .03878 . x$.

Masoud, G. N., and W. Li. 2015. HIF-1 $\alpha$ pathway: Role, regulation and intervention for cancer therapy. Acta Pharm. Sin. B 5:378389. https://doi.org/10.1016/j.apsb.2015.05.007.

McNeil, C. J., S. O. Hoskin, D. M. Bremner, G. Holtrop, and G. E. Lobley. 2016. Whole-body and splanchnic amino acid metabolism in sheep during an acute endotoxin challenge. Br. J. Nutr. 116:211-222. https://doi.org/10.1017/S0007114516001860.

Meissner, S., F. Hagen, C. Deiner, D. Gunzel, G. Greco, Z. Shen, and J. R. Aschenbach. 2017. Key role of short-chain fatty acids in epithelial barrier failure during ruminal acidosis. J. Dairy Sci. 100:6662-6675. https://doi.org/10.3168/jds.2016-12262.

Memon, R. A., K. R. Feingold, A. H. Moser, W. Doerrler, S. Adi, C. A. Dinarello, and C. Grunfeld. 1992. Differential effects of interleukin-1 and tumor necrosis factor on ketogenesis. Am. J. Physiol. 263:E301-E309. https://doi.org/10.1152/ajpendo.1992.263.2 .E301.

Neogrády, S., P. Galfi, and F. Kutas. 1989. Effects of butyrate and insulin and their interaction on the DNA synthesis of rumen epithelial cells in culture. Experientia 45:94-96. https://doi.org/10 $.1007 / \mathrm{BF} 01990459$.

O'Connor, J. C., R. H. McCusker, K. Strle, R. W. Johnson, R. Dantzer, and K. W. Kelley. 2008. Regulation of IGF-I function by proinflammatory cytokines: At the interface of immunology and endocrinology. Cell. Immunol. 252:91-110. https://doi.org/10 .1016/j.cellimm.2007.09.010.

Pailla, K., M. Y. El-Mir, L. Cynober, and F. Blonde-Cynober. 2001. Cytokine-mediated inhibition of ketogenesis is unrelated to nitric oxide or protein synthesis. Clin. Nutr. 20:313-317. https://doi .org/10.1054/clnu.2001.0421.

Pailla, K., S. K. Lim, J. P. De Bandt, C. Aussel, J. Giboudeau, S. Troupel, L. Cynober, and F. Blonde-Cynober. 1998. TNF- $\alpha$ and IL-6 synergistically inhibit ketogenesis from fatty acids and $\alpha$-ketoisocaproate in isolated rat hepatocytes. JPEN J. Parenter. Enteral Nutr. 22:286-290. https://doi.org/10.1177/ 0148607198022005286 .

Parada, V. D., M. K. De la Fuente, G. Landskron, M. J. Gonzalez, R. Quera, G. Dijkstra, H. J. M. Harmsen, K. N. Faber, and M. A. Hermoso. 2019. Short chain fatty acids (SCFAs)-mediated gut epithelial and immune regulation and its relevance for inflammatory bowel diseases. Front. Immunol. 10:277. https://doi.org/10.3389/ fimmu.2019.00277.

Pastore, S., F. Mascia, S. Gulinelli, S. Forchap, C. Dattilo, E. Adinolfi, G. Girolomoni, F. Di Virgilio, and D. Ferrari. 2007. Stimulation of purinergic receptors modulates chemokine expression in human keratinocytes. J. Invest. Dermatol. 127:660-667. https://doi.org/ $10.1038 /$ sj.jid.5700591.

Paupe, V., and J. Prudent. 2018. New insights into the role of mitochondrial calcium homeostasis in cell migration. Biochem. Biophys. Res. Commun. 500:75-86. https://doi.org/10.1016/j.bbrc 2017.05.039.

Penner, G. B., M. A. Steele, J. R. Aschenbach, and B. W. McBride. 2011. Ruminant Nutrition Symposium: Molecular adaptation of ruminal epithelia to highly fermentable diets. J. Anim. Sci. 89:1108-1119. https://doi.org/10.2527/jas.2010-3378.

Perks, C. M., C. McCaig, and J. M. Holly. 2000. Differential insulinlike growth factor (IGF)-independent interactions of IGF binding protein-3 and IGF binding protein-5 on apoptosis in human breast cancer cells. Involvement of the mitochondria. J. Cell. Biochem. 80:248-258. https://doi.org/10.1002/1097-4644(20010201)80: $2<248:$ :AID-JCB140 $>3.0$. CO $; 2-4$.

Peterson, L. W., and D. Artis. 2014. Intestinal epithelial cells: Regulators of barrier function and immune homeostasis. Nat. Rev. Immunol. 14:141-153. https://doi.org/10.1038/nri3608.

Peuhkuri, K., H. Vapaatalo, and R. Korpela. 2010. Even low-grade inflammation impacts on small intestinal function. World J. Gastroenterol. 16:1057-1062. https://doi.org/10.3748/wjg.v16.i9.1057.

Plaizier, J. C., M. Danesh Mesgaran, H. Derakhshani, H. Golder, E. Khafipour, J. L. Kleen, I. Lean, J. Loor, G. Penner, and Q. Zebeli. 2018. Review: Enhancing gastrointestinal health in dairy cows. Animal 12(Suppl. 2):s399-s418. https://doi.org/10.1017/ S1751731118001921.

Plaizier, J. C., E. Khafipour, S. Li, G. N. Gozho, and D. O. Krause. 2012. Subacute ruminal acidosis (SARA), endotoxins and health consequences. Anim. Feed Sci. Technol. 172:9-21. https://doi.org/ 10.1016/j.anifeedsci.2011.12.004.

Pott, J., and M. Hornef. 2012. Innate immune signalling at the intestinal epithelium in homeostasis and disease. EMBO Rep. 13:684698. https://doi.org/10.1038/embor.2012.96.

Richardson, R. A., and H. I. Davidson. 2003. Nutritional demands in acute and chronic illness. Proc. Nutr. Soc. 62:777-781. https://doi .org/10.1079/PNS2003302.

Sehested, J., L. Diernaes, P. D. Moller, and E. Skadhauge. 1999. Ruminal transport and metabolism of short-chain fatty acids (SCFA) in vitro: Effect of SCFA chain length and $\mathrm{pH}$. Comp. Biochem. Physiol. A Mol. Integr. Physiol. 123:359-368. https://doi.org/10 .1016/S1095-6433(99)00074-4.

Simpson, H. L., N. C. Jackson, F. Shojaee-Moradie, R. H. Jones, D. L. Russell-Jones, P. H. Sonksen, D. B. Dunger, and A. M. Umpleby 2004. Insulin-like growth factor I has a direct effect on glucose and protein metabolism, but no effect on lipid metabolism in type 1 diabetes. J. Clin. Endocrinol. Metab. 89:425-432. https://doi.org/ 10.1210/jc.2003-031274.

Sivaprakasam, S., Y. D. Bhutia, S. Yang, and V. Ganapathy. 2017. Short-chain fatty acid transporters: Role in colonic homeostasis. Compr. Physiol. 8:299-314. https://doi.org/10.1002/cphy.c170014.

Staal-van den Brekel, A. J., M. A. Dentener, A. M. Schols, W. A. Buurman, and E. F. Wouters. 1995. Increased resting energy expenditure and weight loss are related to a systemic inflammatory response in lung cancer patients. J. Clin. Oncol. 13:2600-2605. https://doi.org/10.1200/JCO.1995.13.10.2600.

Steele, M. A., J. Croom, M. Kahler, O. AlZahal, S. E. Hook, K. Plaizier, and B. W. McBride. 2011. Bovine rumen epithelium undergoes rapid structural adaptations during grain-induced subacute ruminal acidosis. Am. J. Physiol. Regul. Integr. Comp. Physiol. 300:R1515-R1523. https://doi.org/10.1152/ajpregu.00120.2010.

Stumpff, F. 2018. A look at the smelly side of physiology: Transport of short chain fatty acids. Pflugers Arch. 470:571-598. https://doi .org/10.1007/s00424-017-2105-9.

Thibault, R., F. Blachier, B. Darcy-Vrillon, P. de Coppet, A. Bourreille, and J. P. Segain. 2010. Butyrate utilization by the colonic 
mucosa in inflammatory bowel diseases: A transport deficiency. Inflamm. Bowel Dis. 16:684-695. https://doi.org/10.1002/ibd.21108.

Thibault, R., P. De Coppet, K. Daly, A. Bourreille, M. Cuff, C. Bonnet, J. F. Mosnier, J. P. Galmiche, S. Shirazi-Beechey, and J. P. Segain. 2007. Down-regulation of the monocarboxylate transporter 1 is involved in butyrate deficiency during intestinal inflammation. Gastroenterology 133:1916-1927. https://doi.org/10.1053/j.gastro 2007.08.041.

Vancamelbeke, M., T. Laeremans, W. Vanhove, K. Arnauts, A. S. Ramalho, R. Farre, I. Cleynen, M. Ferrante, and S. Vermeire. 2019. Butyrate does not protect against inflammation-induced loss of epithelial barrier function and cytokine production in primary cell monolayers from patients with ulcerative colitis. J. Crohns Colitis 13:1351-1361. https://doi.org/10.1093/ecco-jcc/jjz064.

Villodre Tudela, C., C. Boudry, F. Stumpff, J. R. Aschenbach, W. Vahjen, J. Zentek, and R. Pieper. 2015. Down-regulation of monocarboxylate transporter 1 (MCT1) gene expression in the colon of piglets is linked to bacterial protein fermentation and pro-inflammatory cytokine-mediated signalling. Br. J. Nutr. 113:610-617. https://doi.org/10.1017/S0007114514004231.

Wickersham, M., S. Wachtel, T. Wong Fok Lung, G. Soong, R. Jacquet, A. Richardson, D. Parker, and A. Prince. 2017. Metabolic stress drives keratinocyte defenses against Staphylococcus aureus infection. Cell Rep. 18:2742-2751. https://doi.org/10.1016/j.celrep 2017.02.055.

Wiese, B. I., P. Gorka, T. Mutsvangwa, E. Okine, and G. B. Penner. 2013. Short communication: Interrelationship between butyrate and glucose supply on butyrate and glucose oxidation by ruminal epithelial preparations. J. Dairy Sci. 96:5914-5918. https://doi .org/10.3168/jds.2013-6677.

Xiao, T., S. Wu, C. Yan, C. Zhao, H. Jin, N. Yan, J. Xu, Y. Wu, C. Li, Q. Shao, and S. Xia. 2018. Butyrate upregulates the TLR4 expression and the phosphorylation of MAPKs and NK- $\kappa \mathrm{B}$ in colon cancer cell in vitro. Oncol. Lett. 16:4439-4447. https://doi.org/10 .3892/ol.2018.9201.

Zagari, F., M. Jordan, M. Stettler, H. Broly, and F. M. Wurm. 2013. Lactate metabolism shift in $\mathrm{CHO}$ cell culture: The role of mito- chondrial oxidative activity. N. Biotechnol. 30:238-245. https:// doi.org/10.1016/j.nbt.2012.05.021.

Zhan, K., X. Gong, Y. Chen, M. Jiang, T. Yang, and G. Zhao. 2019. Short-chain fatty acids regulate the immune responses via $\mathrm{G}$ protein-coupled receptor 41 in bovine rumen epithelial cells. Front. Immunol. 10:2042. https://doi.org/10.3389/fimmu.2019.02042.

Zhang, R., W. Zhu, and S. Mao. 2016. High-concentrate feeding upregulates the expression of inflammation-related genes in the ruminal epithelium of dairy cattle. J. Anim. Sci. Biotechnol. 7:42. https:// doi.org/10.1186/s40104-016-0100-1.

Zhang, S., G. Bories, C. Lantz, R. Emmons, A. Becker, E. Liu, M. M. Abecassis, L. Yvan-Charvet, and E. B. Thorp. 2019. Immunometabolism of Phagocytes and Relationships to Cardiac Repair. Front. Cardiovasc. Med. 6:42. https://doi.org/10.3389/fcvm.2019 .00042 .

Zhang, Z., Z. Zi, E. E. Lee, J. Zhao, D. C. Contreras, A. P. South, E. D. Abel, B. F. Chong, T. Vandergriff, G. A. Hosler, P. E. Scherer, M. Mettlen, J. C. Rathmell, R. J. DeBerardinis, and R. C. Wang. 2018. Differential glucose requirement in skin homeostasis and injury identifies a therapeutic target for psoriasis. Nat. Med. 24:617-627. https://doi.org/10.1038/s41591-018-0003-0

Zhao, K., Y. H. Chen, G. B. Penner, M. Oba, and L. L. Guan. 2017. Transcriptome analysis of ruminal epithelia revealed potential regulatory mechanisms involved in host adaptation to gradual high fermentable dietary transition in beef cattle. BMC Genomics 18:976. https://doi.org/10.1186/s12864-017-4317-y.

Zheng, Y., Y. Song, Q. Han, W. Liu, J. Xu, Z. Yu, R. Zhang, and N. Li. 2018. Intestinal epithelial cell-specific IGF1 promotes the expansion of intestinal stem cells during epithelial regeneration and functions on the intestinal immune homeostasis. Am. J. Physiol Endocrinol. Metab. 315:E638-E649. https://doi.org/10.1152/ ajpendo.00022.2018.

\section{ORCIDS}

G. B. Penner (1) https://orcid.org/0000-0002-6396-2130 